\author{
SANDIA REPORT \\ SAND2009-7854 \\ Unlimited Release \\ Printed November 2009
}

\title{
Predicting the Performance of Local Seismic Networks Using Matlab and Google Earth
}

Eric P. Chael

Prepared by

Sandia National Laboratories

Albuquerque, New Mexico 87185 and Livermore, California 94550

Sandia is a multiprogram laboratory operated by Sandia Corporation, a Lockheed Martin Company, for the United States Department of Energy's

National Nuclear Security Administration under Contract DE-AC04-94AL85000.

Approved for public release; further dissemination unlimited. 
Issued by Sandia National Laboratories, operated for the United States Department of Energy by Sandia Corporation.

NOTICE: This report was prepared as an account of work sponsored by an agency of the United States Government. Neither the United States Government, nor any agency thereof, nor any of their employees, nor any of their contractors, subcontractors, or their employees, make any warranty, express or implied, or assume any legal liability or responsibility for the accuracy, completeness, or usefulness of any information, apparatus, product, or process disclosed, or represent that its use would not infringe privately owned rights. Reference herein to any specific commercial product, process, or service by trade name, trademark, manufacturer, or otherwise, does not necessarily constitute or imply its endorsement, recommendation, or favoring by the United States Government, any agency thereof, or any of their contractors or subcontractors. The views and opinions expressed herein do not necessarily state or reflect those of the United States Government, any agency thereof, or any of their contractors.

Printed in the United States of America. This report has been reproduced directly from the best available copy.

Available to DOE and DOE contractors from

U.S. Department of Energy

Office of Scientific and Technical Information

P.O. Box 62

Oak Ridge, TN 37831

Telephone: $\quad$ (865) 576-8401

Facsimile: (865) 576-5728

E-Mail: reports@adonis.osti.gov

Online ordering: http://www.osti.gov/bridge

Available to the public from

U.S. Department of Commerce

National Technical Information Service

5285 Port Royal Rd.

Springfield, VA 22161

Telephone: $\quad$ (800) 553-6847

Facsimile: (703) 605-6900

E-Mail: $\quad$ orders@ntis.fedworld.gov

Online order: $\quad$ http://www.ntis.gov/help/ordermethods.asp?loc=7-4-0\#online

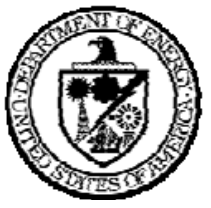


SAND2009-7854

Unlimited Release

Printed November 2009

\title{
Predicting the Performance of Local Seismic Networks Using Matlab and Google Earth
}

\author{
Eric P. Chael \\ Ground-Based Monitoring R\&E \\ Sandia National Laboratories \\ P.O. Box 5800 \\ Albuquerque, New Mexico 87185-MS0404
}

\begin{abstract}
We have used Matlab and Google Earth to construct a prototype application for modeling the performance of local seismic networks for monitoring small, contained explosions. Published equations based on refraction experiments provide estimates of peak ground velocities as a function of event distance and charge weight. Matlab routines implement these relations to calculate the amplitudes across a network of stations from sources distributed over a geographic grid. The amplitudes are then compared to ambient noise levels at the stations, and scaled to determine the smallest yield that could be detected at each source location by a specified minimum number of stations. We use Google Earth as the primary user interface, both for positioning the stations of a hypothetical local network, and for displaying the resulting detection threshold contours.
\end{abstract}




\section{CONTENTS}

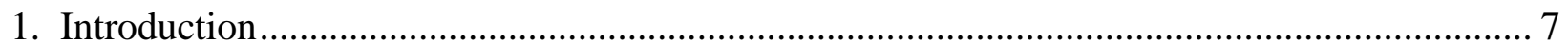

2. Ground motion estimates for small explosions.................................................................... 9

3. Matlab routines for local-network modeling …………....................................................... 13

4. Google Earth as the user interface ………………............................................................. 15

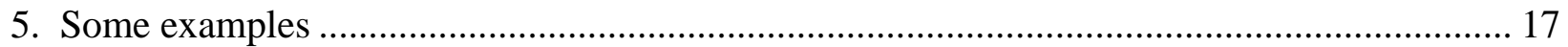

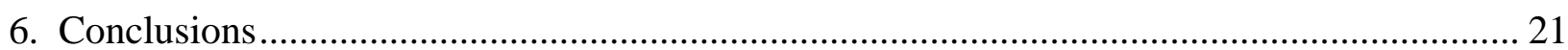

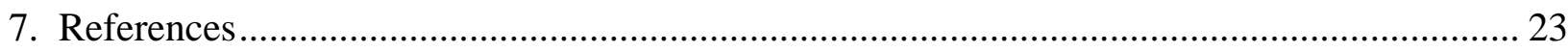

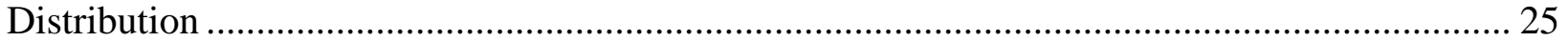

\section{FIGURES}

Figure 1. Amplitude decay with distance. Peak ground velocity vs. scaled distance for explosions in hard rock. Figure from Kohler and Fuis (1992).

Figure 2. Yield scaling. Peak ground velocity vs. shot size for explosions in hard rock. The regression line has a slope of 0.5061. Figure from Kohler and Fuis (1992).

Figure 3. A three-station network. A hypothetical local network in the Rio Grande Rift in northern New Mexico. Stations were positioned as placemarks in Google Earth. The image spans about $40 \mathrm{~km}$ on a side, and the stations are separated by $25-30 \mathrm{~km}$.

Figure 4. Performance estimate for the three-station network. Detection threshold contours for the local network in Figure 3, based on detection by at least two stations. The image is slightly transparent, so underlying geographic features are still discernible.

Figure 5. A nine-station network. Short-period stations operated by New Mexico Tech near Socorro, NM. This image spans about $140 \mathrm{~km}$ on a side.

Figure 6. Performance estimate for the nine-station network. Detection threshold contours for the network in Figure 5, based on detection by at least three stations. 


\section{NOMENCLATURE}

CASPAR Close Access Sensors, Planning, and Analysis Research DEM digital elevation model

GIS Geographic Information System

IMS International Monitoring System

KML Keyhole Markup Language

NNSA National Nuclear Security Administration

rms root mean square

SNR signal-to-noise ratio

USGS United States Geological Survey

XML Extensible Markup Language 


\section{INTRODUCTION}

Sandia's Close Access Sensors, Planning, and Analysis Research (CASPAR) project was established to define and improve the capabilities of local seismic and acoustic monitoring of small explosions. Current global monitoring networks, such as the IMS, were designed to have stations within regional or teleseismic distances of most of the world's continental areas. With such station spacing, these networks can reliably detect seismic events with magnitudes above 3.0 to 3.5 worldwide, consistent with their design goals (Hafemeister, 2007). This level corresponds to well-coupled underground explosions of approximately a few hundred tons or larger. To push monitoring levels significantly below magnitude 3 or so will require stations within local distances of particular sites, that is at ranges of $200 \mathrm{~km}$ or less. Local networks operate in many places around the world, primarily to address seismic hazards in active zones or areas that have suffered damaging earthquakes in the past. Local-network bulletins commonly report events with magnitudes well below 2. Much is known about the operational capabilities of local networks, but some questions remain for local monitoring of explosions. The CASPAR project is intended to identify and address such questions.

The CASPAR project plan defines three research areas that can help prepare the United States to be ready to conduct effective local monitoring at desired sites. The first topic, Sensors and Systems, focuses on the required hardware capabilities for local stations. Ideally, such stations would be small, low-power, and autonomous, yet offer advanced performance and high reliability. Under CASPAR we plan to document required hardware specifications and identify commercially-available components (sensors, digitizers, processors, etc.) that meet those specs. Later, we could address system-architecture issues, which would cover all aspects of a deployable unit, including power and communications. The second research area for CASPAR is Signal Processing and Analysis. This will address effective methods for analyzing local seismic and acoustic signals in order to detect and characterize events of concern. The analysis routines should be suitable for implementation within the field system, to reduce data communication to a minimum. In FY09, we have begun this effort by exploring the range of amplitudes and frequencies to be expected from small local explosions. The third research area is Deployment Planning and Performance Estimation. We are developing software applications for modeling the performance of hypothetical deployments of local stations, similar to existing network simulation programs used for teleseismic and regional networks. For this, we will need the best available information on source scaling of small explosions, and on signal propagation within $200 \mathrm{~km}$ of the epicenter.

This report covers our initial work on Deployment Planning and Performance Estimation. We have developed prototype software to predict the detection threshold of a hypothetical local network of arbitrary configuration. The predictions are based on source coupling and amplitudedistance relations developed by Kohler and Fuis (1992) using data recorded in western North America. The prediction equations and network threshold calculations have been implemented as functions in Matlab. The primary user interface is provided by Google Earth, which offers powerful geographic display capabilities for any data that can be represented in its standard KML format. Network configuration and visualization of the resulting performance are both handled within Google Earth. 
First we give an overview of the study done by Kohler and Fuis to develop equations for predicting the maximum ground motions at local ranges from small explosions. Next we describe how their results are used to construct maps of the minimum yields which should be detectable by multiple stations of a hypothetical local network. Following this is a discussion of how we use Google Earth both to select locations for network stations, and then to display the corresponding threshold maps. Some sample performance estimates are presented for a hypothetical 3-station local network, and for an existing network with 9 stations.

The current local-network performance tool has some limitations which will be addressed in ongoing work on the CASPAR project. Unlike more mature network modeling routines available for teleseismic and regional networks, our code does not yet incorporate the statistical behavior of the seismic arrivals or the background noise. Also, the code makes a single, broadband prediction of the expected maximum ground velocity at some distance from a source. This needs to be expanded to more realistically handle the frequency-dependent behavior of individual seismic arrivals. Because Kohler and Fuis relied on data collected in western North America, the distance decay parameters we have incorporated are most appropriate for similar geologic environments. Eventually we intend to add a range of seismic propagation parameters in order to improve the predictions for different regions. 


\section{GROUND MOTION ESTIMATES FOR SMALL EXPLOSIONS}

Most of the published information on seismic ground motion amplitudes at local ranges has been derived from earthquake recordings. Such results typically express amplitude as a function of range and event magnitude. Examples include numerous articles on calibration equations for local magnitude scales such as $\mathrm{M}_{\mathrm{L}}$. For local monitoring of small explosions, we are more immediately interested in source yields than seismic magnitudes. The mining and construction industries use explosives frequently, and have developed empirical relations for predicting maximum seismic and acoustic amplitudes based on yield and range. For these industries, the chief concerns are safety and damage mitigation, so the distance range is usually restricted to within several kilometers or so. A closer analogue to local blast monitoring is provided by geophysical profiling. The U. S. Geological Survey (USGS) and similar agencies in other countries often conduct refraction experiments to study crustal structure. These typically rely on a series of shallow, tamped explosions with charge weights of 100 to $1000 \mathrm{~kg}$. Seismometers are deployed along profiles extending up to a few hundred kilometers from the shots. To facilitate the planning and permitting of such experiments, Kohler and Fuis $(1989,1992)$ compiled thousands of measurements of peak vertical ground velocities observed along dozens of refraction lines, primarily in Alaska and Arizona. They investigated the relationships between the signal amplitudes and source-to-receiver range, and also examined the coupling effects of differing emplacement media at the shotpoints. They fit their data using an equation of the form:

$$
\log (A)=b_{1} \cdot \log (D)+b_{2} \cdot(\log (D))^{2}+c \cdot \log (W)+g
$$

where $\mathbf{A}$ is the peak ground velocity $(\mathrm{cm} / \mathrm{s}), \mathbf{D}$ the epicentral distance $(\mathrm{km})$, and $\mathbf{W}$ the charge weight (kg). The parameters $\mathbf{b}_{\mathbf{1}}$ and $\mathbf{b}_{\mathbf{2}}$ combine to specify the decay with distance, and $\mathbf{c}$ gives the yield scaling. Parameter $\mathbf{g}$ represents the source coupling term, with separate values for dry alluvium, wet alluvium, hard rock, lake, and ocean emplacements. 


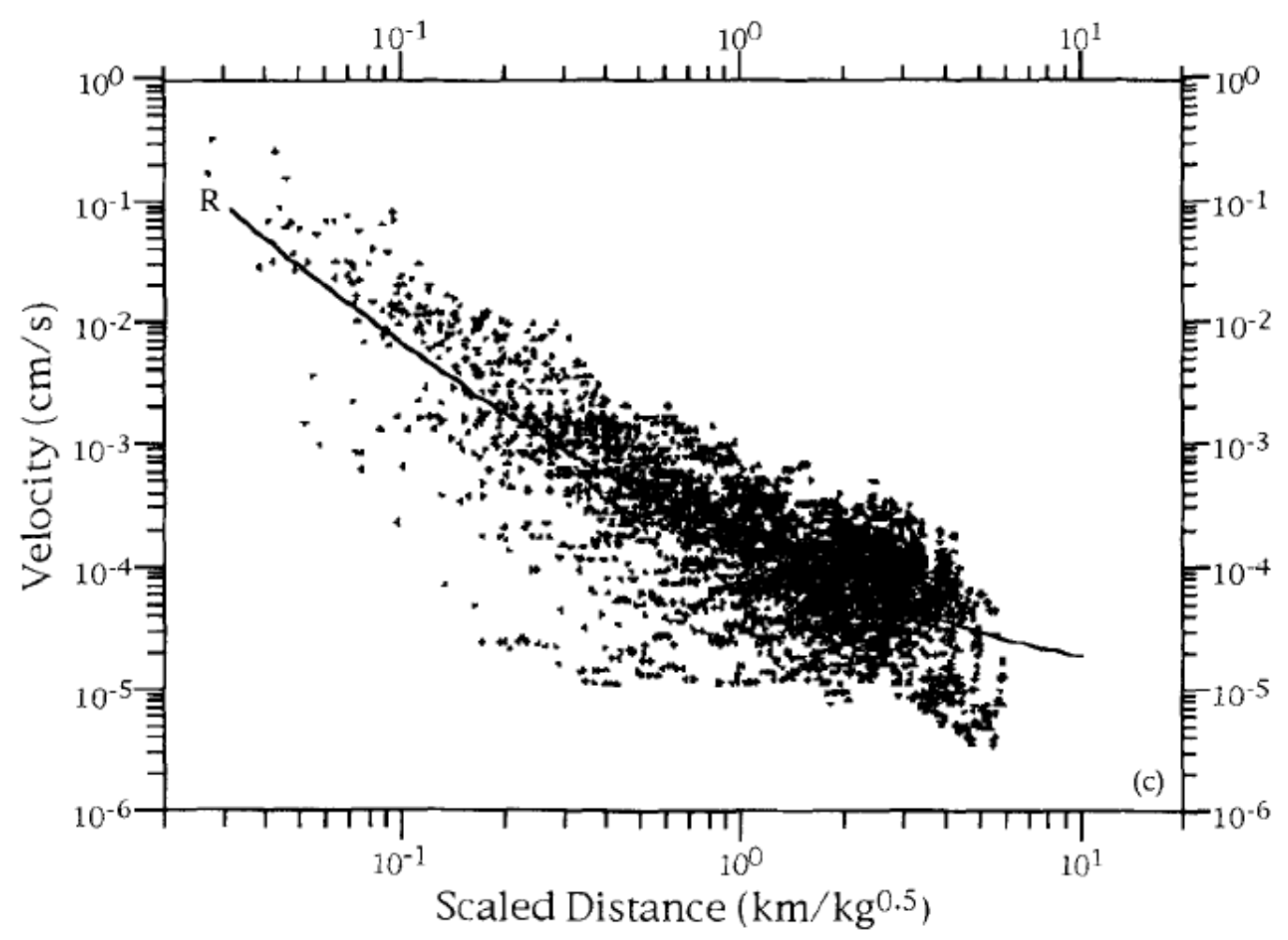

Figure 1. Amplitude decay with distance. Peak ground velocity vs. scaled distance for explosions in hard rock. Figure from Kohler and Fuis (1992).

Figure 1 shows the refraction data for shots in hard rock, together with the corresponding prediction curve given by the above equation. Note that the amplitudes are plotted against the scaled distance $\mathbf{D} / \sqrt{ } \mathbf{W}$. The actual source-to-receiver distances varied from 0.1 to $500 \mathrm{~km}$.

Scaling the distance by the square root of yield as in Figure 1 is equivalent to fixing $\mathbf{c}$ at 0.5 in Equation 1. This is very close to the value of 0.5061 which Kohler and Fuis (1992) obtained from their data regressions. Figure 2, also from their paper, shows the observed yield dependence for hard-rock shots, and the regression line with the favored slope. The yields span only two orders of magnitude, and the amplitudes display considerable scatter. Because of this, these data alone do not convincingly constrain the yield scaling. Most available magnitude-yield relations for nuclear tests (e.g., Murphy, 1996; Vergino and Mensing, 1990) employ scaling coefficients c in the range of 0.7 to 0.9 . Brocher (2003) showed that the nuclear scaling laws are reasonably consistent with magnitudes of small, contained conventional explosions. For our prototype network performance modeling, we have adopted the Kohler and Fuis amplitude-distance curve for a 1000-kg shot, but fixed the yield scaling coefficient $\mathbf{c}$ at 0.75 . 


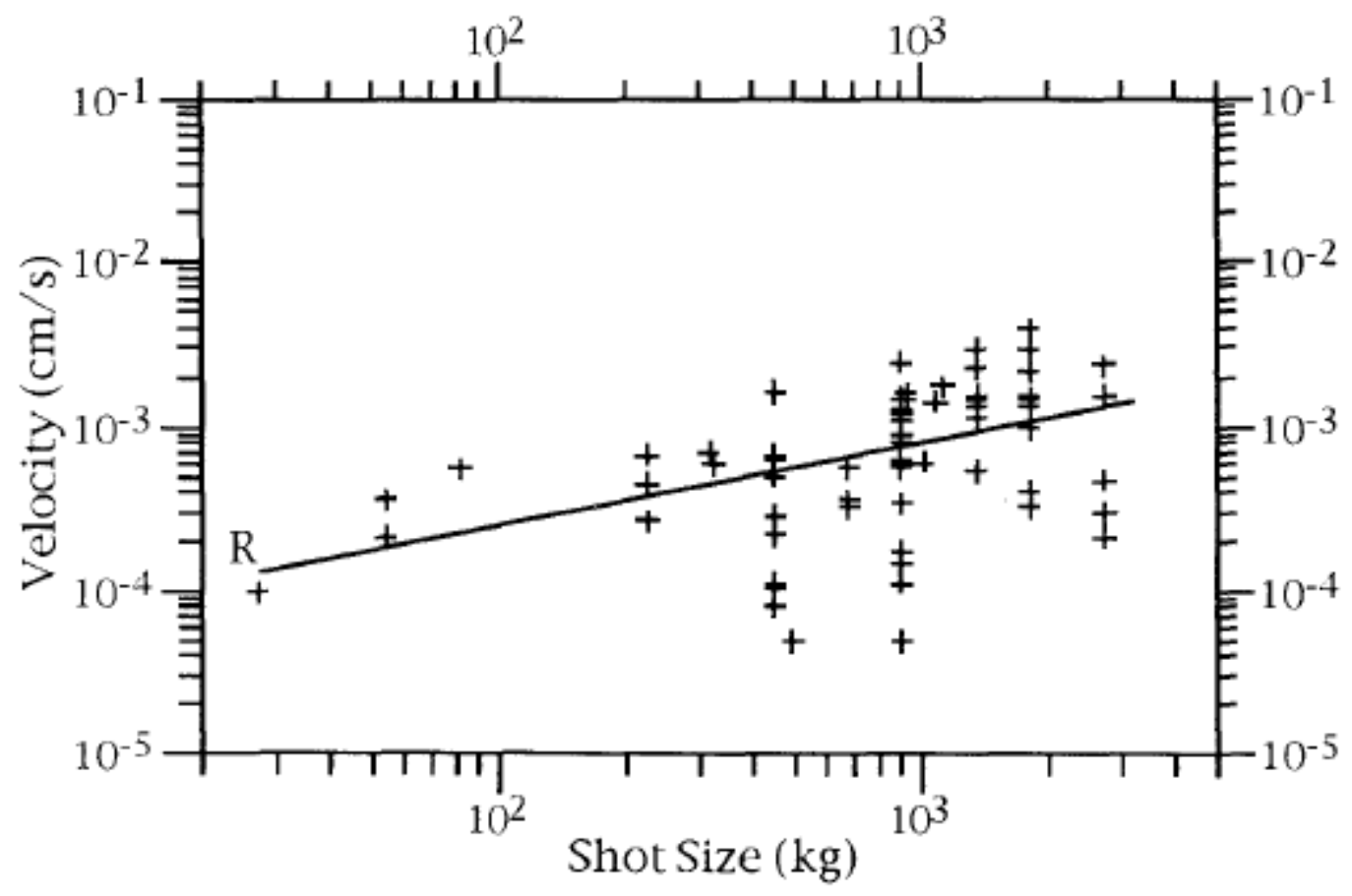

Figure 2. Yield scaling. Peak ground velocity vs. shot size for explosions in hard rock. The regression line has a slope of 0.5061. Figure from Kohler and Fuis (1992).

All of the data used by Kohler and Fuis were collected in the tectonic setting of western North America, mostly in Alaska and Arizona. Given the scatter in the samples, those authors could not reliably resolve differences in decay rates among the refraction lines in various locales. As a result, they reported fixed values for both of the propagation parameters $\mathbf{b}_{\mathbf{1}}$ and $\mathbf{b}_{2}$. No doubt other geologic provinces will behave differently, and require changes to these values or to the form of Equation 1 to accurately represent the amplitude decay. In related work, we have been reviewing $\mathrm{M}_{\mathrm{L}}$ calibrations for numerous operating networks around the world. We intend to adapt some of those calibrations so that we can better predict explosion amplitudes in areas other than western North America, particularly for stable regions likely to be quite different. 


\section{MATLAB ROUTINES FOR LOCAL-NETWORK MODELING}

We have developed functions in Matlab for estimating the minimum detectable explosion yield for a local network. The sources are assumed to be fully-contained, well-tamped underground shots. Decoupling, either in a cavity or by underburying to produce cratering, has not been considered so far. An input file specifies the proposed station locations of the network. Based on the station layout, a uniform rectangular grid of latitudes and longitudes is defined which extends somewhat beyond the network in all directions. The gridpoints are then used as source locations for modeling the network response to explosions of some yield. Peak velocity amplitudes at each station are estimated first for a 1-ton explosion at each gridpoint, using Equation 1. The ratio of the predicted shot amplitude to a specified rms noise level is then tested against a desired detection threshold. Next, the source yield is scaled either up or down, as described in the previous section, to find the minimum yield expected to exceed the detection threshold at a specified minimum number of stations. The yield thus determined is then recorded as the network threshold for that grid location. Once this has been completed over the entire grid, a shaded relief map can be generated from the latitude, longitude, minimum-yield triplets, then saved as an image file.

For the current prototype routine, the user can select among the five source media considered by Kohler and Fuis (wet alluvium, dry alluvium, hard rock, lake, ocean). One also specifies the ambient rms noise level in microns/second, the detection threshold (as a ratio of peak signal amplitude to the rms noise floor), and the number of detecting stations needed to declare a network detection.

In ongoing development of the prototype, we will add a number of features to provide the user with greater control over the modeling. Additionally, dialog boxes and menus will make the software easier to use. Currently, the main modeling routine is called from the Matlab command line, with inputs entered as function parameters. We will allow the user to modify the default spacing and extent of the modeling grid. A single background noise level is presently used for all stations, and we will change this to allow for independent noise levels at each site. The yield scaling exponent, currently fixed at 0.75 , will be made adjustable over some range. Related to this, we could include a magnitude-yield formula, so that the resulting threshold map can be shown as either yield or magnitude contours.

Eventually, we intend to allow for different decay behavior than the Kohler and Fuis model. This can be done either by allowing the user to vary the $\mathbf{b}_{\mathbf{1}}$ and $\mathbf{b}_{\mathbf{2}}$ values for Equation 1, or perhaps by allowing one to choose from a number of published decay models, such as those used for $\mathrm{M}_{\mathrm{L}}$ calculations in various regions. Many $\mathrm{M}_{\mathrm{L}}$ decay relations employ spreading and attenuation terms - the former is the same as the $\mathbf{b}_{\mathbf{1}}$ term, the latter would replace the $\mathbf{b}_{\mathbf{2}}$ term with one of the form $\mathbf{b}_{3} \cdot \mathbf{D}$. Because decoupling is a realistic concern for small explosions, we could add a decoupling ratio as an input option. To improve the statistical validity, we need to include information on signal and noise variances, then specify a desired confidence level as part of the network detection criteria. Alternatively, this might best be achieved by incorporating local signal modeling within NetCAP, a separate application under development for regional and teleseismic network modeling. 


\section{GOOGLE EARTH AS THE USER INTERFACE}

We selected Google Earth to be the primary means of displaying both the network geometry and the resulting detection threshold maps. This is a freely-available Geographic Information System (GIS) that provides us with powerful 3D visualization capabilities while requiring minimal programming to exchange data with Matlab. The downloadable version of Google Earth itself either installs or connects over the internet to a wide assortment of global geographic information. Overhead imagery is draped across a detailed digital elevation model (DEM), and the user can easily zoom to view any level of detail, or rotate the viewing angle to change the perspective for a scene. Nearly any type of information referenced by latitude and longitude can be either positioned in the display or immediately accessed by clicking a marker. Many organizations now provide internet access to their databases in Google Earth's standard format, allowing one to combine any assortment of information in the display.

For data input and output, Google Earth uses a format known as KML, for Keyhole Markup Language. This is an extension of the Web-standard XML format. Most GIS vendors now support KML, so we should be able to accommodate almost any GIS product as a front end for network modeling. A wide variety of objects can be positioned on the globe using KML, including point markers, paths, polygons, and overlaid images. Complete information about any object, including any descriptive metadata, can be viewed by selecting the item in the display. Below is a portion of a basic KML file that defines three geographic locations near Albuquerque.

\section{KML Sample}

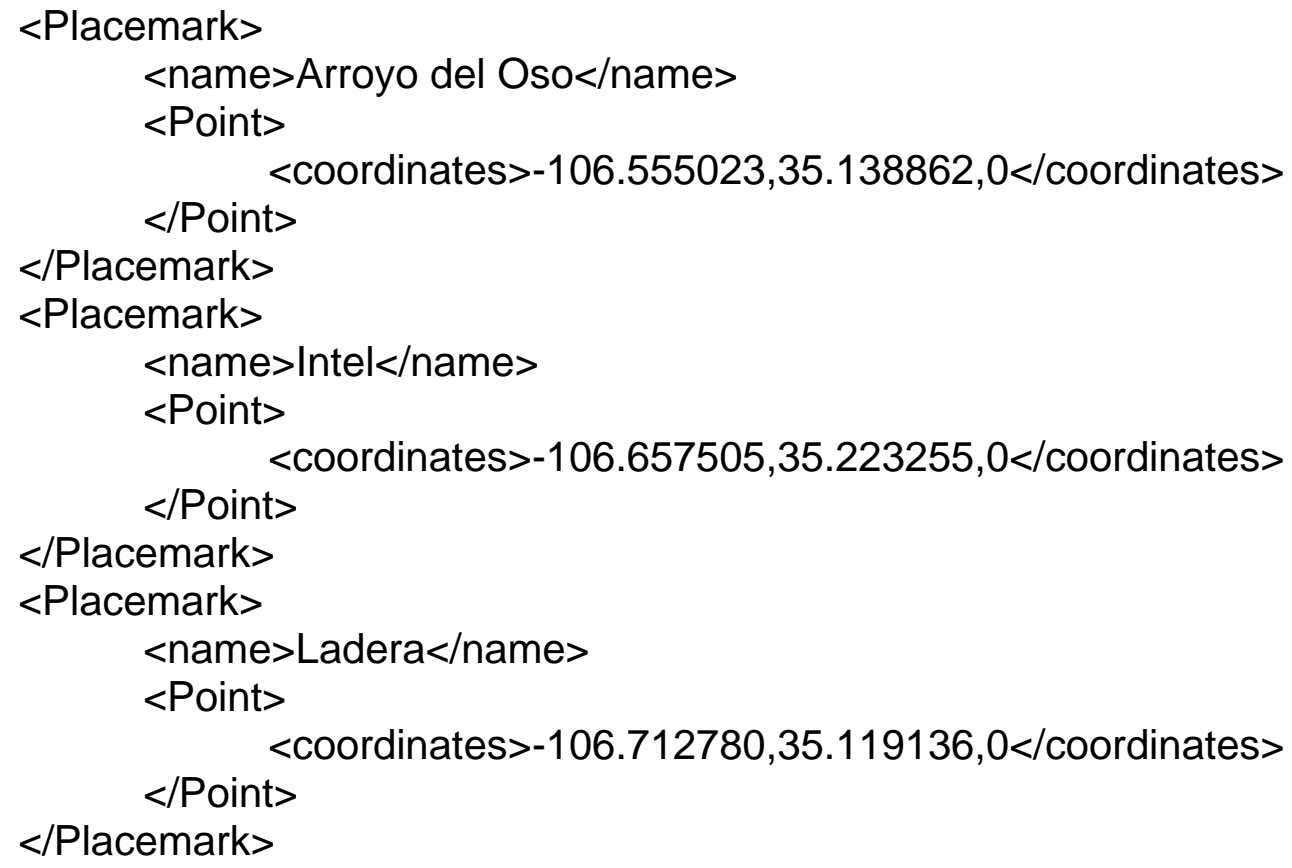


With a small amount of Matlab code, we can read similar files that contain station locations, and write out KML files that position the resulting detection threshold images. The easiest way to define station locations for a hypothetical local network is to create a group of placemarks directly in Google Earth. This group can then be saved to a KML file using the application's 'File' menu. For an existing network, one can create a KML file for the station locations using a text editor, starting with the sample above as a template.

The next step is to launch the performance modeling routine from Matlab, and select the recently-created file of station locations. Remaining parameters for the modeling are specified, then Matlab calculates the yield threshold contours as described in preceding sections. Matlab writes the contour plot as a jpeg image file, then generates a companion KML file that references the image file and defines its latitude and longitude limits. Matlab can then send the image directly into Google Earth, which displays the image of detection contours over the station locations. Examples of this process for two different networks are presented in the next section. 


\section{SOME EXAMPLES}

For the first example, we model the performance of a simple three-station network. Figure 3 shows an overhead image of a portion of the Rio Grande Rift in northern New Mexico. The Rio Grande runs down the image from north to south to the right of center. East of the river are the Sangre de Cristo mountains, and several volcanic features spread across the valley to the west. The yellow lines that cross the west and southwest of the view are U. S. highways, and state highways appear as lighter lines on the eastern side.

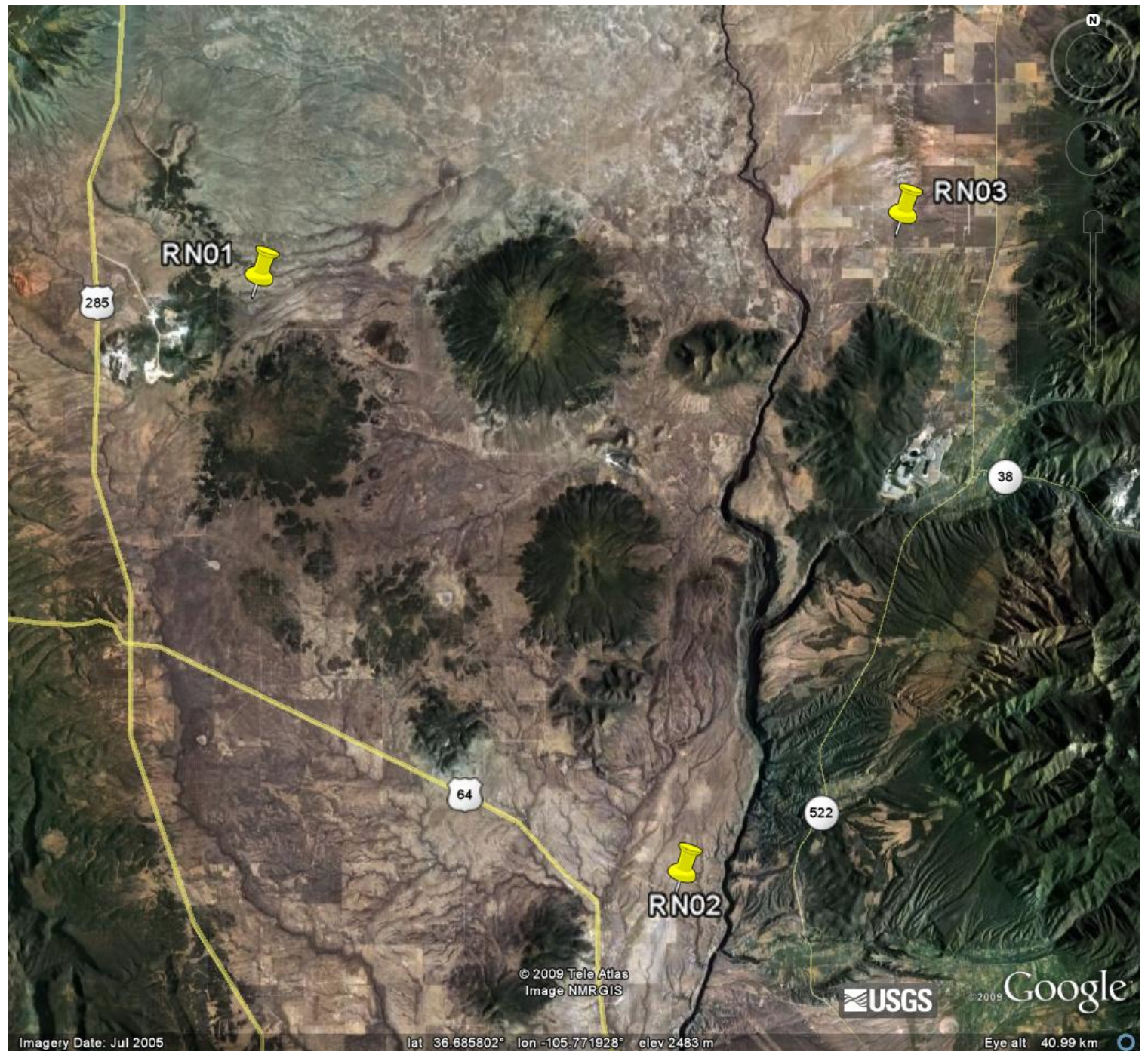

Figure 3. A three-station network. A hypothetical local network in the Rio Grande Rift in northern New Mexico. Stations were positioned as placemarks in Google Earth. The image spans about $40 \mathrm{~km}$ on a side, and the stations are separated by $25-30 \mathrm{~km}$.

Using the 'Add Placemark' tool in Google Earth, we added three prospective seismic stations, shown as yellow pushpins. The sides of this triangular network are 25 to $30 \mathrm{~km}$ long. Someone planning an actual deployment can use the imagery and overlays in Google Earth to consider 
such things as roads, rail lines, industrial and agricultural activity, landforms, vegetation, etc. Once the station locations have been selected, one saves the information to a KML file.

The next step is to run the network performance modeling routine from Matlab. After the code completes the calculations over a grid spanning the network, the resulting detection threshold image can be sent from Matlab to be displayed by Google Earth. Figure 4 superimposes a threshold image on the scene of Figure 3. For this example, the network detection criteria required two stations with peak amplitudes four times the assumed rms background noise level. Using the two-station criterion, one expects the lowest thresholds midway between each pair of stations, and this is just what we see in the cloverleaf pattern of Figure 4. Each distinct shade spans one-tenth of a log unit in detectable explosion yield; the darkest blue color in two of the leaves corresponds to yields between 0.04 and 0.05 tons, and the yellow-green color around the edges of the figure to yields of 0.20 to 0.25 tons.

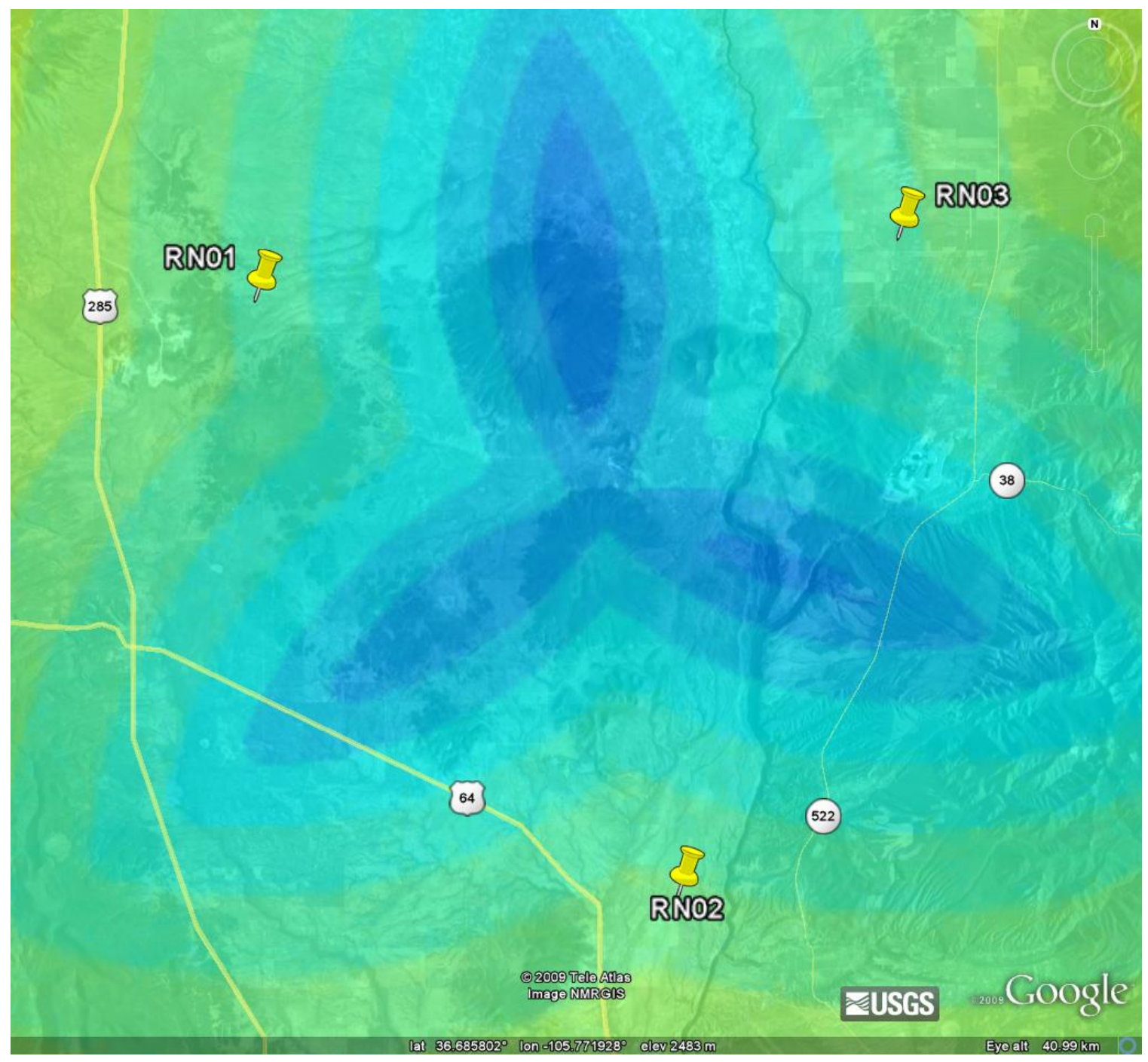

Figure 4. Performance estimate for the three-station network. Detection threshold contours for the local network in Figure 3, based on detection by at least two stations. The image is slightly transparent, so underlying geographic features are still discernible. 
Next we consider a somewhat larger local network. For this we decided to model the explosion detection capability of an existing network. The New Mexico Institute of Mining and Technology operates several stations across the Rio Grande Rift in central New Mexico, to monitor seismic activity related to the mid-crustal Socorro magma body (Balch et al., 1997). This feature has been delineated in the shallow crust by its propensity to block S waves travelling across it. Figure 5 displays the locations of nine of New Mexico Tech's short period stations. This portion of their network extends about $70 \mathrm{~km}$ north-south, by $60 \mathrm{~km}$ east-west.

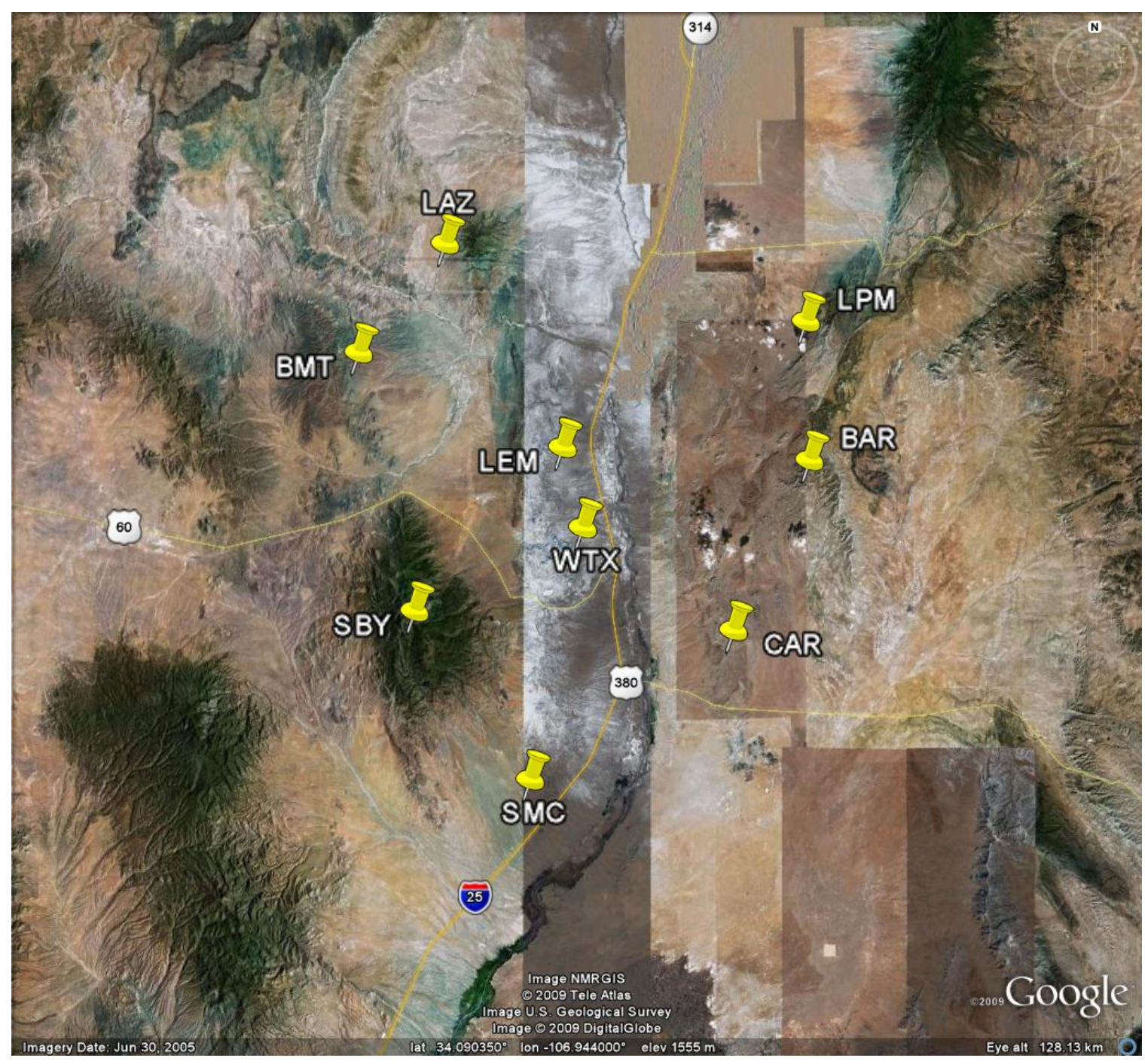

Figure 5. A nine-station network. Short-period stations operated by New Mexico Tech near Socorro, NM. This image spans about $140 \mathrm{~km}$ on a side.

Figure 6 shows a detection threshold estimate for these nine stations. This time, we have required detectable arrivals at three stations, again with peak amplitudes four times the noise level. Contour intervals are the same as in Figure 4, and the orange shade in the far northeast and southwest corners represents yields above 1 ton.. The network geometry leads to a more complex 
pattern than in the previous example, with a number of small pockets of blue in the central part of the net. The deepest of these corresponds to yields below 0.1 ton.

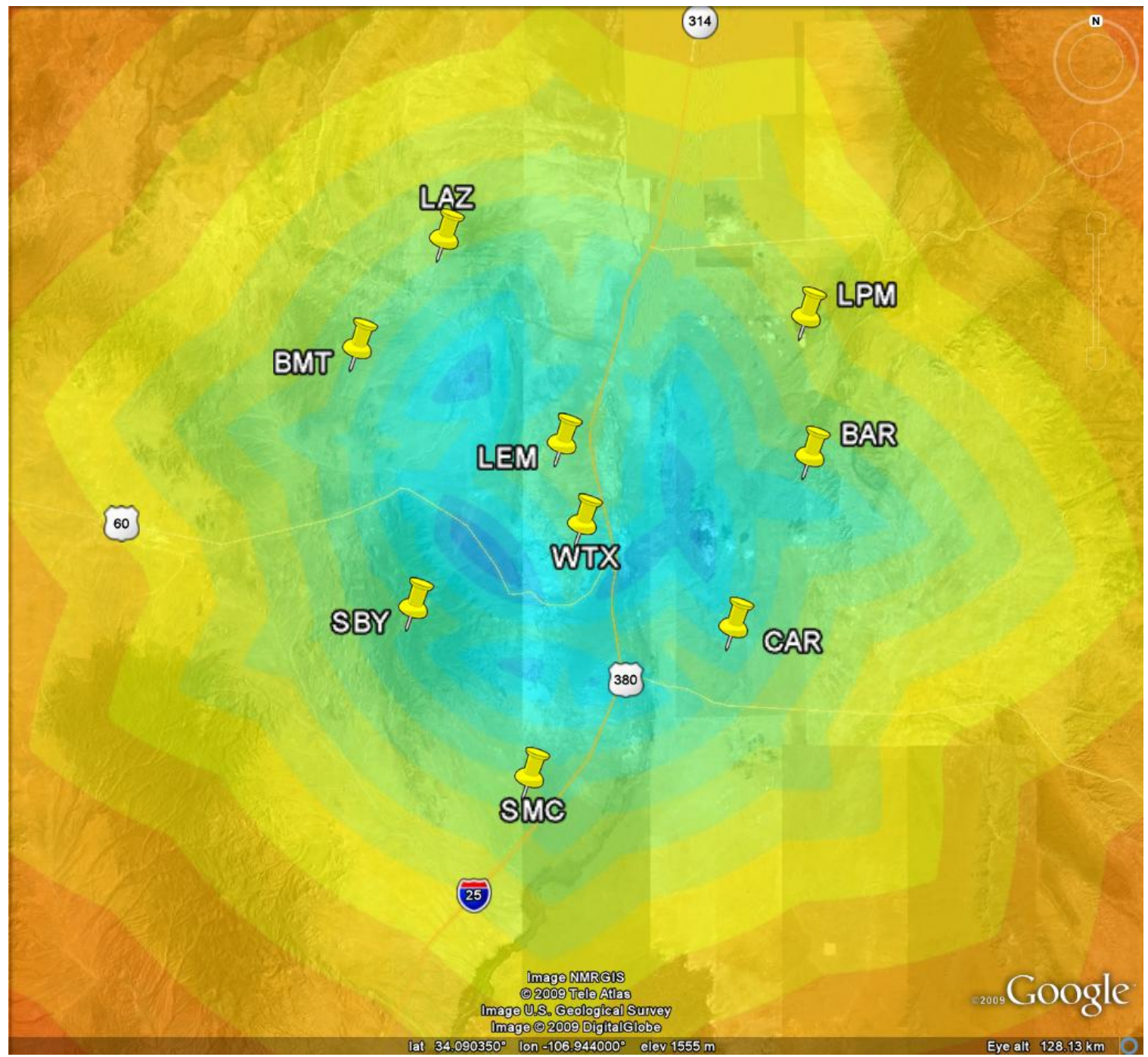

Figure 6. Performance estimate for the nine-station network. Detection threshold contours for the network in Figure 5, based on detection by at least three stations.

These examples illustrate how the routines we have written can be used to estimate the detection performance of either an existing local network or a proposed one. They can also be used for sensitivity studies, to determine the changes in capability caused by adding or moving a station, or by changing the station or network detection criteria. 


\section{CONCLUSIONS}

We have used Matlab and Google Earth to rapidly prototype an application for estimating the detection performance of local seismic networks. Because our primary interest is in monitoring small explosions, we currently calculate the detection threshold in terms of the yield of a contained shot. We adopted the equations of Kohler and Fuis (1992) for predicting the peak velocity from a 1-ton charge as a function of distance up to $300 \mathrm{~km}$. Instead of their preferred square-root scaling with yield, we set the scaling factor $\mathbf{c}$ in Equation 1 to 0.75. This is more consistent with typical amplitude-yield relations for nuclear explosions above $1 \mathrm{kt}$, and with Brocher's (2003) compilation of data from conventional explosions of $1 \mathrm{~kg}$ to $1 \mathrm{kt}$. The routines can be used to model either existing or proposed networks. For the latter case, Google Earth provides an especially convenient platform for choosing station locations, because of its ability to flexibly display a wide variety of available information for any geographic region.

The next step will be to validate the current algorithms by comparing some predictions to the operational experience of existing networks. The Socorro network is a good candidate for this, because New Mexico Tech also operates an explosives test facility, so we should be able to get good information on source properties of some known explosions, and correlate that with the seismic network's bulletins. We can refine the values used for background noise and the signalto-noise ratio (SNR) detection threshold to match the real situation. Other networks we might consider for this include the New England Seismic Network run by Boston College, or the New Madrid Seismic Network operated by the University of Memphis. Both of these should record many explosions from quarries or mines at local to near-regional distances.

As the current project continues, we plan to improve the present prototype in a number of ways. User interfaces for setting the various input parameters will make the software easier to use. Amplitude decay relations besides that of Kohler and Fuis will be added. For this, we will start with published decay relations used by different established networks for measuring local magnitude $\mathrm{M}_{\mathrm{L}}$. This is especially needed for stable regions, because the Kohler and Fuis decay curve represents the behavior of signals in tectonically-active western North America. As part of this step, we will add an option to display the results as either yield or magnitude thresholds. Also, we need to include both the signal and noise variances, then recast the detection modeling as a statistical estimate at some desired confidence level. This approach is standard practice for global-network performance estimates. We omitted the statistical behavior for now in order to accelerate the development of an initial prototype.

Longer term, we would like to handle the local P and S arrivals separately, and possibly allow for $2 \mathrm{D}$ variations in propagation in well-studied areas. The current formulation predicts the peak time-domain velocity for frequencies above 1-2 Hz. Eventually we could introduce frequency dependence by modeling the spectra of local arrivals at several points across the bandwidth. At that time we would probably consider incorporating local-distance modeling within the NetCAP effort, a separate NNSA-funded project for modeling the performance of regional and teleseismic networks. 


\section{REFERENCES}

Balch, R. S., H. E. Hartse, A. R. Sanford, and K. Lin (1997). A new map of the geographic extent of the Socorro mid-crustal magma body, Bull. Seism. Soc. Am. 87, 174-182.

Brocher, T. M. (2003). Detonation charge size versus coda magnitude relations in California and Nevada, Bull. Seism. Soc. Am. 93, 2089-2105.

Hafemeister, D. (2007). Progress in CTBT monitoring since its 1999 Senate defeat, Science and Global Security 15, 151-183.

Kohler, W. M., and G. S. Fuis (1989). Empirical relationship among shot size, shotpoint site condition, and recording distance for 1984-1987 U. S. Geological Survey seismic-refraction data, U. S. Geol. Survey Open-File Rept. 89-675, 113 pp.

Kohler, W. M., and G. S. Fuis (1992). Empirical dependence of seismic ground velocity on the weight of explosives, shotpoint site condition, and recording distance for seismic-refraction data, Bull. Seism. Soc. Am. 82, 2032-2044.

Murphy, J. R. (1996). Types of seismic events and their source descriptions, in Monitoring a Comprehensive Test Ban Treaty, E. S. Husebye and A. M. Dainty (editors), 225-245.

Vergino, E. S., and R. W. Mensing (1990). Yield estimation using regional $\mathrm{m}_{\mathrm{b}}(\mathrm{Pn})$, Bull. Seism. Soc. Am. 80, 656-674. 


\section{DISTRIBUTION}

1 Randy Bell

NNSA Office of Nonproliferation Research and Development/NA-22

1000 Independence Avenue SW

Washington, DC 20585

1 Leslie Casey

NNSA Office of Nonproliferation Research and Development/NA-22

1000 Independence Avenue SW

Washington, DC 20585

1 John Ziagos

NNSA Office of Nonproliferation Research and Development/NA-22

1000 Independence Avenue SW

Washington, DC 20585

1 John Dwyer

Air Force Technical Applications Center/TTR

1030 S. Highway A1A

Patrick AFB, FL 32925-3002

1 Mark Woods

Air Force Technical Applications Center/TTR

1030 S. Highway A1A

Patrick AFB, FL 32925-3002

1 Bill Walter

Lawrence Livermore National Laboratory

MS L-046

PO Box 808

Livermore, CA 94551

1 Ward Hawkins

Los Alamos National Laboratory

MS F665

PO Box 1663

Los Alamos, NM 87545

1 MS0401 Dorthe Carr 5527

1 MS0401 Ben Hamlet 5527

1 MS0401 Chris Young 5527

1 MS0404 Eric Chael 5736

1 MS0404 Bobby Corbell 5736 


$\begin{array}{lllll}1 & \text { MS0404 } & \text { Darren Hart } & 5736 & \\ 1 & \text { MS0404 } & \text { Tim McDonald } & 5736 & \\ 1 & \text { MS0404 } & \text { John Merchant } & 5736 & \\ 1 & \text { MS0404 } & \text { Randy Rembold } & 5736 & \\ 1 & \text { MS0404 } & \text { Megan Resor } & 5736 & \\ & & & & \\ 2 & \text { MS9018 } & \text { Central Technical Files } & 8944 & \\ 1 & \text { MS0899 } & \text { Technical Library } & 9536 & \text { (electronic copy) }\end{array}$




\section{Sandia National Laboratories}

